Bangladesh J. Bot. 41(1): 75-83, 2011 (June)

\title{
ALLEVIATION OF ADVERSE EFFECTS OF DROUGHT STRESS ON COMMON BEAN (PHASEOLUS VULGARIS L.) BY EXOGENOUS APPLICATION OF HYDROGEN PEROXIDE
}

\author{
Salwa Mohamed Abass and Heba Ibrahim Mohamed* \\ Biological and Geological Sciences Department, Faculty of Education, \\ Ain Shams University Roxy, Cairo, Egypt
}

Key words: Drought, Phaseolus vulgaris, Common bean, Advanced effect, Hydrogen peroxide

\begin{abstract}
Effects of seed pretreatment by hydrogen peroxide $\left(\mathrm{H}_{2} \mathrm{O}_{2}\right)$ on drought tolerance in common bean plants (Phaseolus vulgaris L.) were studied. Drought stress caused highly significant decrease in growth parameters, photosynthetic pigments, total carbohydrates and phytohormones. An increase drought stress caused highly significant increase in compatible solutes and polyamine contents as antioxidants and ABA contents in shoots of common bean plants. $\mathrm{H}_{2} \mathrm{O}_{2}$-pretreatment of seeds enhanced all the above parameters than the waterpretreated seeds (control) under drought condition. Results suggested that $\mathrm{H}_{2} \mathrm{O}_{2}$, a stress signal could trigger the activation of antioxidants in seeds which persists in the plants to alleviate the oxidative damage leading to improvements in physiological attributes for the plants growth under drought.
\end{abstract}

\section{Introduction}

Drought is a major abiotic stress that affects agricultural systems and food production and also induces several physiological, biochemical and molecular responses in several crop plants which give rise to excess concentrations of active oxygen species (AOS) resulting in oxidative damage at cellular level (Foyer and Noctor 2002). Drought inhibits the photosynthesis of plants causing changes of chlorophyll contents, damage the photosynthetic apparatus and decreases the activities of Calvin cycle enzymes (Monakhova and Chernyadev 2002).

Generally, the environmental stresses especially drought stress, give rise to accumulation of soluble carbohydrates, proline and free amino acids as well as antioxidants compounds. These solutes are low molecular weight, highly soluble compounds that are non toxic at high cellular concentration and protect cellular components from dehydration injury, thus are referred to as osmoprotectants and compatible solutes (Reddy et al. 2004, Shao et al. 2005).

Polyamines play an important role in maintaining membrane and nucleic acid integrity under most of the stress conditions (Erdei et al. 1996). However, both ionic deficiency and salinity, and osmotic stresses may influence polyamine metabolism in different manners and polyamines may have different and specific functions under these stress conditions (Zhou et al. 1995).

Water stress markedly reduced the amounts of auxins, gibberellins and cytokinin, while it reversibly raised the amounts of ABA (Abdalla and El-Khoshiban 2007).

Hydrogen peroxide is produced under various abiotic and biotic stresses. It is relatively stable and diffuses through membranes (Vranova et al. 2002), thus exogenous application of hydrogen peroxide at low concentrations stimulated and enhanced resistance to drought (He et al. 2009). $\mathrm{H}_{2} \mathrm{O}_{2}$ can serve as a second messenger in signal transduction pathways, leading to stress acclimation. Available information suggest that $\mathrm{H}_{2} \mathrm{O}_{2}$ directly regulates the expression of numerous genes involved in plant defense and the related pathways such as antioxidant enzymes, defense proteins and transcription factors (Hung et al. 2005).

*Corresponding author. < hebaibrahim79@yahoo.com>. 
Common bean (Phaseolus vulgaris L., Fabaceae) is an important crop which is sensitive to water deficit when compared to other crops (Cruz et al. 1998). Therefore, it is important to elucidate drought tolerance mechanisms of this crop in order to improve its agronomic performances by exogenous application of hydrogen peroxide. Thus, this study aimed to explore the evaluation effects of hydrogen peroxide treatment for drought stress to better understanding of the physiological and biochemical mechanisms involved.

\section{Materials and Methods}

Seeds of common bean plants (Phaseolus vulgaris L.) were obtained from the Agriculture Research Center, Ministry of Agriculture, Giza, Egypt. Seeds were sterilized with 1\% sodium hypochlorite for $5 \mathrm{~min}$ and rinsed with distilled water and divided into two groups. In the first group, the seeds were soaked in hydrogen peroxide (2\%) for $4 \mathrm{hrs}$ and then air dried. Ten seeds were sown in each pot $(25 \mathrm{~cm}$ in diam) containing equal amount of homogeneous loamy clay soil. These pots were irrigated with $80 \%$ (serve as control), 60 and $40 \%$ of hold water capacity. In the second group, the seeds were soaked in distilled water for $4 \mathrm{hrs}$ and then air dried. The seeds were sown in each pot and were irrigated with 80,60 and $40 \%$ of hold water capacity. The experiment was conducted under natural conditions (day length $12-14 \mathrm{hrs}$, at $20-22^{\circ} \mathrm{C}$ and $70 \%$ humidity). After 60 days of sowing the plant samples were collected to determine certain morphological characters (shoot and root lengths and fresh and dry weights of shoots and roots) in addition to photosynthetic pigments, total carbohydrate, total soluble sugars, total free amino acids, proline, polyamine (putrescine, spermidine and spermine) and plant phytohormones (IAA, GA 3 and ABA).

Chlorophyll $a, b$ and carotenoids were determined following Vernon and Seely (1966). Total carbohydrates were determined using the colorimetric method as described by Dubois et al. (1956). Total soluble sugars were estimated in ethanol extract of plant tissue by the phenolsulphoric acid method as described by Dubois et al. (1956). Total free amino acids were determined using ninhydrin reagent (Moore and Stein 1954) using pure glycine as standard. Proline content was measured by using the method of Bates et al. (1973).

Putrescine, spermidine and spermine were extracted and determined using TLC according to Mietz and Karmas (1977) and Maijala and Eerola (1993) with some modifications. The method of extraction was essentially similar to that adopted by Shindy and Smith (1975). To estimate the amounts of acidic hormones IAA, $\mathrm{GA}_{3}$ and $\mathrm{ABA}$, the plant hormone fractions and standard ones were methylated according to Vogel (1975).

Data were statistically analyzed using F-test and LSD at 5 and $1 \%$ levels of probability according to SAS-Programme (1982).

\section{Results and Discussion}

The plant growth parameters of canola (shoot and root length, fresh and dry weights of shoots and roots) decreased significantly with increasing drought stress as compared with control plants (Table 1). $\mathrm{H}_{2} \mathrm{O}_{2}$ pretreatment alone or in combination with drought stress showed highly significant increase in all the growth parameters when compared with the control.

Drought stress resulted marked drop in plant growth parameters which may be attributed to damage of oxygen evolving complex of photosystem II and its reaction centers (Subrahmanyam et al. 2006). Hu et al. (2007) also found that shoot fresh weight of maize plants grown under drought stress was reduced as compared to control. Drought stress lowers the soil water potential resulting in reduction of plant growth (Munns 2002). Such decline in shoot and root length in response to drought might be due to either decrease in cell elongation resulting from the inhibiting effect of water shortage on growth promoting hormones which, in turn, led to a decrease in each of 
cell turgor, cell volume and eventually cell growth (Banon et al. 2006), and/or due to blocking up of xylem and phloem vessels thus hindering any translocation through (Lavisalo and Schuber 1998). Moreover, the decline in both fresh and dry weight of shoots and roots of common bean reveals the influence of water in stimulating and regulating the photosynthetic enzymes and growth promoting hormones, which thus influences dry matter production (Monti et al. 2006).

Table 1. Effects of exogenous application of $\mathrm{H}_{2} \mathrm{O}_{2}$ on growth parameters of Phaseolus vulgaris plants under drought stress.

\begin{tabular}{|c|c|c|c|c|c|c|}
\hline Treatment & $\begin{array}{l}\text { Shoot } \\
\text { length } \\
(\mathrm{cm})\end{array}$ & $\begin{array}{l}\text { Root } \\
\text { length } \\
(\mathrm{cm})\end{array}$ & $\begin{array}{c}\text { Fresh wt. } \\
\text { of shoots } \\
(\mathrm{gm})\end{array}$ & $\begin{array}{l}\text { Dry wt. of } \\
\text { shoots } \\
\text { (gm) }\end{array}$ & $\begin{array}{c}\text { Fresh wt. } \\
\text { of roots } \\
(\mathrm{gm})\end{array}$ & $\begin{array}{c}\text { Dry wt. } \\
\text { of roots } \\
(\mathrm{gm})\end{array}$ \\
\hline Control & 18.7 & 21.4 & 5.6 & 0.65 & 1.8 & 0.11 \\
\hline $\mathrm{H}_{2} \mathrm{O}_{2} 2 \%$ & $21.3 * *$ & $24.9 * *$ & $6.5^{* *}$ & $0.75 * *$ & $2.5 * *$ & $0.17 * *$ \\
\hline Hold water capacity $60 \%$ & $16.5^{* * *}$ & $19.6 * * *$ & $5.2 * * *$ & $0.55^{* * *}$ & $1.6^{* * *}$ & $0.09 * * *$ \\
\hline $\begin{array}{l}\text { Hold water capacity } 60 \%+ \\
\qquad \mathrm{H}_{2} \mathrm{O}_{2} 2 \%\end{array}$ & $23.7 * *$ & $23.3^{* *}$ & $7.1 * *$ & $0.83 * *$ & $2.4 * *$ & $0.16^{* *}$ \\
\hline Hold water capacity $40 \%$ & $15.1 * * *$ & $17.6^{* * *}$ & $3.8 * * *$ & $0.42 * * *$ & $1.2 * * *$ & $0.06 * * *$ \\
\hline $\begin{array}{l}\text { Hold water capacity } 40 \%+ \\
\qquad \mathrm{H}_{2} \mathrm{O}_{2} \%\end{array}$ & $20.9 * *$ & $22.0 * *$ & $6.0^{* *}$ & $0.69 * *$ & $2.0 * *$ & $0.13 * *$ \\
\hline LSD at $5 \%$ & 0.514 & 0.415 & 0.183 & 0.023 & 0.079 & 0.006 \\
\hline LSD at $1 \%$ & 0.739 & 0.597 & 0.263 & 0.034 & 0.113 & 0.010 \\
\hline
\end{tabular}

**Highly significant increase. ${ }^{* * *}$ Highly significant decrease.

Ren et al. (2000) who observed that exogenous application of $\mathrm{H}_{2} \mathrm{O}_{2}$ to wheat enhanced the root growth and fresh weight under drought stress. $\mathrm{H}_{2} \mathrm{O}_{2}$ enhance cell division and promoted the secondary wall formation (Potikha et al. 1999). Anonymous (2002) also found that $\mathrm{H}_{2} \mathrm{O}_{2}$ can stimulate growth of wheat.

Photosynthetic pigments contents in leaves of common bean plants were decreased highly significantly with increasing level of drought stress (Table 2). $\mathrm{H}_{2} \mathrm{O}_{2}$ application alleviates the drought stress by improving pigment contents in leaves of common bean plants. Pretreatment with $\mathrm{H}_{2} \mathrm{O}_{2}$ alone caused highly significant increase in photosynthetic pigments as compared to control one $\left(\mathrm{H}_{2} \mathrm{O}\right)$.

Table 2. Effects of exogenous application of $\mathrm{H}_{2} \mathrm{O}_{2}$ on photosynthetic pigment content (mg/g) of Phaseolus vulgaris plants under drought stress.

\begin{tabular}{lllllc}
\hline Treatment & Chl $a$ & Chl $b$ & Chl $a+b$ & Carotenoids & $\begin{array}{c}\text { Total } \\
\text { pigments }\end{array}$ \\
\hline Control & 12.21 & 3.32 & 15.53 & 1.32 & 16.85 \\
$\mathrm{H}_{2} \mathrm{O}_{2} 2 \%$ & $13.22^{* *}$ & $3.66^{* *}$ & $16.88^{* *}$ & $1.05^{* * *}$ & $17.93^{* *}$ \\
$\mathrm{Hold}$ water capacity $60 \%$ & $10.01^{* * *}$ & $2.72^{* * *}$ & $12.73^{* * *}$ & $1.08^{* * *}$ & $13.81^{* * *}$ \\
Hold water capacity $60 \%+\mathrm{H}_{2} \mathrm{O}_{2} 2 \%$ & $14.09^{* *}$ & $4.56^{* *}$ & $18.65^{* *}$ & $1.51^{* *}$ & $20.16^{* *}$ \\
Hold water capacity 40\% & $7.92^{* * *}$ & $2.24^{* * *}$ & $10.16^{* * *}$ & $0.89^{* * *}$ & $11.05^{* * *}$ \\
Hold water capacity 40\%+ $\mathrm{H}_{2} \mathrm{O}_{2} 2 \%$ & $13.60^{* *}$ & $3.64^{* *}$ & $17.24^{* *}$ & $1.44^{* *}$ & $18.67^{* *}$ \\
LSD at 5\% & 0.384 & 0.129 & 0.508 & 0.039 & 0.540 \\
LSD at $1 \%$ & 0.553 & 0.186 & 0.730 & 0.056 & 0.777 \\
\hline
\end{tabular}

**Highly significant increase. ***Highly significant decrease. 
Significant decrease in chlorophyll $a, b$, carotenoids and total pigments under drought stress amount due to water deficit and mainly because of the damage to chloroplasts by active oxygen species (Agastian et al. 2000). Similarly He et al. (2009) also found that $\mathrm{H}_{2} \mathrm{O}_{2}$ pretreatment enhanced the photosynthetic rate in wheat seedlings under PGE-induced drought condition.

Total carbohydrate contents decreased significantly with increasing level of drought stress (Table 3). Pretreatment of seeds with $\mathrm{H}_{2} \mathrm{O}_{2}$ caused highly significant increase in the same contents in shoots of common bean plants. These results are in accordance with Saleh (2007) who found that mung bean showed a significant decline in carbohydrate content when faced a chilling stress, but treating mung bean with hydrogen peroxide significantly increased carbohydrate content when compared to the positive control.

Table 3. Effects of exogenous application of $\mathrm{H}_{2} \mathrm{O}_{2}$ on total carbohydrate, total soluble sugars, total free amino acid and proline contents of Phaseolus vulgaris plants under drought stress.

\begin{tabular}{lcccc}
\hline Treatments & $\begin{array}{c}\text { Carbohydrate } \\
(\mathrm{mg} / 100 \mathrm{~g} \text { d.wt.) }\end{array}$ & $\begin{array}{c}\text { Soluble sugars } \\
(\mathrm{mg} / 100 \mathrm{~g} \text { d.wt. })\end{array}$ & $\begin{array}{c}\text { Free amino acids } \\
(\mu \mathrm{g} / \mathrm{g} \text { f. wt. })\end{array}$ & $\begin{array}{c}\text { Proline } \\
(\mu \mathrm{g} / \mathrm{g} \text { f.wt. })\end{array}$ \\
\hline Control & 153.50 & 38.03 & 18.65 & 91.30 \\
$\mathrm{H}_{2} \mathrm{O}_{2} \%$ & $231.00^{* *}$ & $48.58^{* *}$ & $22.80^{* *}$ & $97.44^{* *}$ \\
$\mathrm{Hold}$ water capacity $60 \%$ & $141.50^{* * *}$ & $51.55^{* *}$ & $23.58^{* *}$ & $108.37^{* *}$ \\
Hold water capacity $60 \%+\mathrm{H}_{2} \mathrm{O}_{2} 2 \%$ & $204.88^{* *}$ & $67.73^{* *}$ & $33.33^{* *}$ & $116.30^{* *}$ \\
Hold water capacity 40\% & $118.00^{* * *}$ & $67.83^{* *}$ & $46.08^{* *}$ & $116.41^{* *}$ \\
Hold water capacity 40\%+ $\mathrm{H}_{2} \mathrm{O}_{2} 2 \%$ & $168.38^{* *}$ & $81.98^{* *}$ & $50.10^{* *}$ & $126.35^{* *}$ \\
LSD at 5\% & 6.677 & 2.562 & 2.169 & 2.091 \\
LSD at $1 \%$ & 9.601 & 3.685 & 3.119 & 3.006 \\
\hline
\end{tabular}

** Highly significant increase. *** Highly significant decrease.

Total soluble sugars content in shoots of common bean plants significantly increase under drought stress alone or in combination with $\mathrm{H}_{2} \mathrm{O}_{2}$ pretreatment. The increase in sugar concentration may be a result from the degradation of starch (Fischer and Höll 1991). Starch may play an important role in accumulation of soluble sugars in cells. Starch depletion in grapevine leaves was noted by Patakas and Noitsakis (2001) in response to drought stress.

The tolerance mechanism in water-deficit may be associated with accumulation of osmoprotectants such as soluble sugars. The accumulation of soluble sugars is strongly correlated to the acquisition of drought tolerance in plants (Hoekstra and Buitink 2001). The accumulation of soluble sugars compounds protects the cell under stress by balancing the osmotic strength of the cytosol with that of the vacuole and the external environment. The compound also interact with cellular macromolecules as enzymes and stabilize their structure (El-Tayeb 2006). Soluble sugars may also function as a typical osmoprotectant, stabilizing cellular membranes and maintaining turgor.

Soluble sugars can function in two ways, which are difficult to separate: as osmotic agents and as osmoprotectors (Bohnert et al. 1995). As osmoprotectors, sugars stabilize proteins and membranes, most likely substituting the water in the formation of hydrogen bonds with polypeptide polar residues (Crowe et al. 1992) and phospholipid phosphate groups (Strauss and Hauser 1986).

The drought condition caused significant increase in the total free amino acids in shoot of common bean plants. Yadav et al. (1999) reported that amino acids content increased under drought stress apparently due to hydrolysis of proteins in chickpea. Ashraf and Iram (2005) stated that water deficit caused a significant increase in total free amino acids of all plant parts of 
Phaseolus vulgaris and Sesbania aculeata. A maximum increase in free amino acids was observed in leaves and nodules of $P$. vulgaris.

Proline accumulation under drought stress may be that it contributes a protective role as scavenges of reactive oxygen species (ROS), resulted in improved adaptation ability and growth of plants under drought conditions (Turkan and Demiral 2009). Accumulation of proline is an important indicator of drought stress tolerance in higher plants (Ashraf and Iram 2005). Proline, has been suggested as one of the possible means for overcoming osmotic stress caused by the loss of water (Caballero et al. 2005). Proline is a non-protein amino acid that forms in most tissues subjected to water stress and together with sugar, it is readily metabolized upon recovery from drought (Singh et al. 2000). In addition to acting as an osmo-protectant, proline also serves as a sink for energy to regulate redox potentials, as a hydroxyl radical scavenger (Sharma and Dietz 2006), as a solute that protects macromolecules against denaturation and as a means of reducing acidity in the cell (Kishor et al. 2005). However, Vendruscolo et al. (2007) stated that proline might confer drought stress tolerance to wheat plants by increasing the antioxidant system rather than as an osmotic adjustment.

Spermidine, putracine, spermine and total polyamine contents increased significantly in plants under drought stress (Table 4). In addition, pretreatment with $\mathrm{H}_{2} \mathrm{O}_{2}$ caused highly significantly increase in polyamine contents in shoots of common bean as compared to control plants except putracine which showed significant increase when seeds were pretreated with $\mathrm{H}_{2} \mathrm{O}_{2}$ alone.

Table 4. Effects of exogenous application of $\mathrm{H}_{2} \mathrm{O}_{2}$ on polyamine contents of Phaseolus vulgaris plants under drought stress.

\begin{tabular}{lcccc}
\hline Treatments & $\begin{array}{c}\text { Spermidine } \\
(\mathrm{ppm})\end{array}$ & $\begin{array}{c}\text { Putracine } \\
(\mathrm{ppm})\end{array}$ & $\begin{array}{c}\text { Spermine } \\
(\mathrm{ppm})\end{array}$ & $\begin{array}{c}\text { Total polyamine } \\
(\mathrm{ppm})\end{array}$ \\
\hline Control & 1.22 & 21.40 & 1.67 & 24.29 \\
$\mathrm{H}_{2} \mathrm{O}_{2} 2 \%$ & $2.31^{* *}$ & $28.6^{*}$ & $11.73^{* *}$ & $42.64^{* *}$ \\
$\mathrm{Hold}$ water capacity $60 \%$ & $2.75^{* *}$ & $30.98^{* *}$ & $14.2^{* *}$ & $47.93^{* *}$ \\
Hold water capacity 60\%+ $\mathrm{H}_{2} \mathrm{O}_{2} 2 \%$ & $3.38^{* *}$ & $54.96^{* *}$ & $19.83^{* *}$ & $78.17^{* *}$ \\
Hold water capacity 40\% & $5.39^{* *}$ & $80.23^{* *}$ & $24.55^{* *}$ & $110.17^{* *}$ \\
Hold water capacity 40\% $+\mathrm{H}_{2} \mathrm{O}_{2} 2 \%$ & $8.96^{* *}$ & $128.04^{* *}$ & $44.5^{* *}$ & $181.5^{* *}$ \\
LSD at 5\% & 0.45 & 6.53 & 2.32 & 9.25 \\
LSD at $1 \%$ & 0.64 & 9.39 & 3.34 & 13.30 \\
\hline
\end{tabular}

*Significant increase. $* *$ Highly significant increase.

Results show that spermidine, putracine and spermine significantly increased under drought stress alone or in combination with pretreatment of $\mathrm{H}_{2} \mathrm{O}_{2}$. These results confirm with results obtained by Kasukabe et al. (2004) working on transgenic Arabidopsis thaliana who found that plants exhibited a significant increase in spermidine synthase activity and spermidine content in leaves showing enhanced tolerance to various stresses including drought, salinity, freezing and hyperosmosis. The results strongly suggest an important role of spermidine as a signalling regulator in stress signalling pathways, leading to build-up of stress tolerance mechanisms in plants under stress conditions.

Polyamines (PAs) are ubiquitous in both eukaryotes and prokaryotes. The most common PAs in higher plants are putrescine (Put), spermidine (Spd) and spermine (Spm). In plants, PAs are commonly associated with responses to biotic and abiotic stresses and have been shown to function in drought and chilling tolerance in some situations (Kakkar et al. 2000). 
Polyamines are involved in plant defense to environmental stresses (Bouchereau et al. 1999). In general, plant species and cultivars with high stress tolerance are endowed with a great capacity to enhance polyamine biosynthesis in response to environmental stresses including drought. The initiation of polyamine accumulation requires an osmotic signal (Imai et al. 2004) also suggest that an osmotic, rather than ionic effect is the main signal triggering the polyamine response under drought. It may act as a protective for the plasma membrane against stress damage by maintaining membrane integrity (Roy et al. 2005), preventing superoxide-generating NADPH oxidases activation (Shen et al. 2000) or inhibiting protease and RNase activity (Bais and Ravishankar 2002).

Data presented in Table 5 demonstrated that IAA and $\mathrm{GA}_{3}$ levels were markedly reduced in common bean shoots with increasing levels of drought stress when compared with those of the control ( $80 \%$ hold water capacity). ABA content showed highly significant increase proportional to drought stress. The exogenous application of $\mathrm{H}_{2} \mathrm{O}_{2}$ alone or in combination with drought stress caused significant increase in both IAA and $\mathrm{GA}_{3}$ contents. In contrast, $\mathrm{ABA}$ content showed highly significant decrease as compared with control plants.

Table 5. Effects of exogenous application of $\mathrm{H}_{2} \mathrm{O}_{2}$ on phytohormone contents (mg/100 g) of Phaseolus vulgaris plants under drought stress.

\begin{tabular}{llll}
\hline Treatment & IAA & $\mathrm{GA}_{3}$ & ABA \\
\hline Control & 13.30 & 15.04 & 3.45 \\
$\mathrm{H}_{2} \mathrm{O}_{2} 2 \%$ & $17.71^{* *}$ & $31.30^{* *}$ & $2.23^{* * *}$ \\
Hold water capacity $60 \%$ & $7.53^{* * *}$ & $12.90^{* * *}$ & $5.25^{* *}$ \\
Hold water capacity $60 \%+\mathrm{H}_{2} \mathrm{O}_{2} 2 \%$ & $17.24^{* *}$ & $25.32^{* *}$ & $4.34^{* *}$ \\
Hold water capacity $40 \%$ & $6.20^{* * *}$ & $10.04^{* * *}$ & $8.62^{* *}$ \\
Hold water capacity $40 \%+\mathrm{H}_{2} \mathrm{O}_{2} 2 \%$ & $15.08^{* *}$ & $21.43^{* *}$ & $2.71^{* * *}$ \\
LSD at $5 \%$ & 0.78 & 1.27 & 0.35 \\
LSD at $1 \%$ & 1.13 & 1.83 & 0.50 \\
\hline
\end{tabular}

**Highly significant increase. ${ }^{* * * H i g h l y ~ s i g n i f i c a n t ~ d e c r e a s e . ~}$

Phytohormones regulate the protective responses of plants against both biotic and abiotic stresses by means of synergistic or antagonistic actions referred to as signaling crosstalk. IAA and $\mathrm{GA}_{3}$ levels were markedly reduced in drought stressed common bean plants as compared with those of the control while reversibly raised the abscisic acid (ABA). These results were similar to those of Zhang et al. (2006) and Abdalla and El-Khoshiban (2007) who found that water stress decreased the content of each of $\mathrm{GA}_{3}, \mathrm{GA}_{4}$, IAA and zeatin whereas it increased $\mathrm{ABA}$ values. Abdalla (2011) also found that drought stress in Lupinus albus gradually declined the contents of all growth ptomoting hormones (auxins, gibberellins and cytokinins) while reversibly raised the abscisic acid (ABA) amount below and above those of the untreated controls respectively.

Drought stress appeared to inhibit the biosynthesis of auxins and gibberellins and/or increase their degradation (Poljakoff-Mayber and Lerner1993). Furthermore, Shi et al. (1994) working on maize seedlings proved that under water stress induced by polyethylene glycol, IAA and $\mathrm{GA}_{3}$ content declined, while ABA content increased.

\section{Reference}

Abdalla MM 2011. Beneficial effects of diatomite on the growth, the biochemical contents and polymorphic DNA in Lupinus albus plants grown under water stress. Agric. Biol. J. N. Am. 2(2): 207-220. 
Abdalla MM and NH El-Khoshiban 2007. The influence of water stress on growth, relative water content, photosynthetic pigments, some metabolic and hormonal contents of two Triticum aestivum cultivars. J. Applied Sci. Res. 3(12): 2062-2074.

Agastian P, SJ Kingsley and M Vivekanandan 2000. Effect of salinity on photosynthesis and biochemical characteristics in mulberry genotypes. Photosynthetica 38: 287-290.

Anonymous 2002. Report by the Mass Governor's Advisory Council on Radiation Protection. Center for Nuclear Technology and Society at Worcester Polytechnic Institute, Worcester. http://cnts. wpi.edu: 9000/rsh/dd3/_database.jsp

Ashraf M and AT Iram 2005. Drought stress induced changes in some organic substances in nodules and other plant parts of two potential legumes differing in salt tolerance. Flora 200: 535-546.

Bais HP and GA Ravishankar. 2002. Role of polyamines in the ontogeny of plants and their biotechnological applications. Plant Cell Tiss. Organ Cult. 69: 1-34.

Banon SJ, J Ochoa, JA Franco, JJ Alarcon and MJ Sanchez-Blanco 2006. Hardening of oleander seedlings by deficit irrigation and low air humidity. Environ. Exp. Bot. 56: 36-43.

Bates LS, RP Waldren and LD Teare 1973. Determination of proline for water-stress studies. Plant Soil 39: 205-207.

Bohnert HJ, DE Nelson and RG Jensen 1995. Adaptations to environmental stresses. Plant Cell 7: 10991111.

Bouchereau A, A Aziz, F Larher and J Martin-Tanguy 1999. Polyamines and environmental challenges: recent development. Plant Sci. 140: 103-125.

Caballero JI, CV Verduzco, J Galan and ESD Jimenez 2005. Proline accumulation as a symptom of drought stress in maize: a tissue differentiation requirement. J. Exp. Environ. Bot. 39(7): 889-897.

Crowe JH, FA Hoekstra and LM Crowe 1992. Anhydrobiosis. Annu. Rev. Physiol. 54: 579-599.

Cruz de Carvalho MH, D Laffray and P Louguet 1998. Comparison of the physiological responses of Phaseolus vulgaris and Vigna unguiculata cultivars when submitted to drought conditions. Environ. Exp. Bot. 40: 197-207.

Desikan RMK Cheung, A Clarke, S Golding, M Sagi, R Fluhr 2004. Hydrogen peroxide is a common signal for darkness- and ABA-induced stomatal closure in Pisum sativum. Funct. Plant Biol. 31: 913-920.

Dubois M, KA Gilles, JK Hamilton, PA Rebers and F Smith 1956. Colorimetric method for determination of sugars and related substances. Anal. Chem. 28: 350-356.

El-Tayeb MA 2006. Differential response of two Vicia faba cultivars to drought: growth, pigments, lipid peroxidation, organic solutes, catalase and peroxidase activity. Acta Agronomica Hungarica 54: 1, 2537.

Erdei L, Z Szegletes, K Barabás and A Pestenácz 1996. Responses in polyamine under osmotic and salt stress in sorghum and maize seedlings. J. Plant Physiol. 147: 599-603.

Fischer C and W Höll 1991. Food reserves of Scots pine (Pinus sylvestris L.). I. Seasonal changes in the carbohydrate and fat reserves of pine needles. Trees 5: 187-195.

Foyer $\mathrm{CH}$ and G Noctor 2002. Oxygen processing in photosynthesis: regulation and signaling. New Phytol. 146: $359-388$.

He L. Z Gao and E Li 2009, Pretreatment of seed with $\mathrm{H}_{2} \mathrm{O}_{2}$ enhances drought tolerance of wheat (Triticum aestivum L.) seedlings. Afri. J. Biotech. 8(22): 6151-6157.

Hoekstra FA and J Buitink 2001. Mechanisms of plant dessiccation tolerance. Trends Plant Sci. 8: 431-438.

$\mathrm{Hu}$ Y, Z Burucs, S Tucher and U Schmidhalter 2007. Short-term effects of drought and salinity on mineral nutrient distribution along growing leaves of maize seedlings. Envir. Exp. Bot. 60: 268-275.

Hung SH, CW Yu and $\mathrm{CH}$ Lin 2005. Hydrogen peroxide functions as a stress signal in plants. Bot. Bull. Acad. Sin. 46: 1-10.

Imai R, A Ali, HR Pramanik, K Nakaminami, N Sentoku and H Kato 2004. A distinctive class of spermidine synthase is involved in chilling response in rice. J Plant Physiol. 161: 883-886.

Kakkar RK, PK Nagar, PS Ahuja and VK Rai 2000. Polyamines and plant morphogenesis. Biol. Plant 43: $1-11$. 
Kasukabe Y, L He, K Nada, S Misawa, I Ihara and S Tachibana 2004. Over expression of spermidine synthase enhances tolerance to multiple environmental stresses and up-regulates the expression of various stress-regulated genes in transgenic Arapidopsis thaliana. Plant Cell Physiol. 45: 712-722.

Kishor PBK, S Sangama, RN Amrutha, PS Laxmi, KR Naidu and KS Rao 2005. Regulation of proline biosynthesis degradation, uptake and transport in higher plants: its implications in plant growth and abiotic stress tolerance. Curr. Sci. 88(3): 424-438.

Lavisolo C and A Schuber 1998. Effects of water stress on vessel size xylem hydraulic conductivity in Vitis vinifera L. J. Exp. Bot. 49: 321, 693-700.

Maijala RL and SH Eerola 1993. Contaminant lactic acid bacteria of dry sausages produce histamine and tyramine. Meat Sci. 35: 387-395.

Mietz JL and E Karmas 1977. Chemical quality index of canned tuna as determined by high pressure liquid chromatography. J Food Sci. 42: 155-158.

Monakhova OF and II Chernyadev 2002. Protective role of kartolin-4 in wheat plants exposed to soil drought. Appl. Biochem. Microbiol. 38: 373-380.

Monti A, MT Amaducci, G Pritoni and G Verturi 2006. Variation in carbon isotope discrimination during growth and at different organs in sugar beet (Beta vulgaris L.). Field Crops Res. 98: 157-163.

Moore S and WH Stein 1954. A Modified ninhydrin reagent for the photometric determination of amino acids and related compounds. J. Biol. Chem. 211: 907-913.

Munns R 2002. Comparative physiology of salt and water stress. Plant Cell Environ. 25: 239-250.

Patakas A and B Noitsakis 2001. Leaf age effects on solute accumulation in water stressed grapevines. J. Plant Physiol. 158: 63- 69.

Poljakoff-Mayber A and HR Larner 1993. Plants in saline environments. In: Handbook of Plant and Crop Stresses. Pessarkali M. (Ed), pp. 65-96. Marcel Dekkor Inc., New York.

Potikha TS, CC Collins, DI Johnson, DP Delmer and A Levine 1999. The involvement of hydrogen peroxide in the differentiation of secondary walls in cotton fibers. Plant Physiol. 119: 849-58

Reddy AR, RK Ramachandra, V Chaitanya and M Vivekanandan 2004. Drought-induced responses of photosynthesis and antioxidant metabolism in higher plants. J. Plant Physiol. 161:1189-1202.

Ren H, X Chen, G Sun and Y Wang 2000. Response of wheat seedlings with different drought resistance to water deficiency and $\mathrm{NaCl}$ stresses. Ying Yong Sheng Tai Xue Bao. 5: 718-22

Roy P, K Niyogi, DN SenGupta and B Ghosh 2005. Spermidine treatment to rice seedlings recovers salinity stress-induced damage of plasma membrane and PM-bound H+-ATPase in salt-tolerant and saltsensitive rice cultivars. Plant Sci. 168: 583-591.

Saleh AAH 2007. Amelioration of chilling injuries in mung bean (Vigna radiate L.) seedlings by paclobutrazol, abscisic acid and hydrogen peroxide. Am. J. Plant Physiol. 2(6): 318-332.

SAS-Programme 1982. SAS user,s Guide Statistics SAS Institute, INC, Raleiegh,. North Carolina. 584 pp.

Shao HB, ZS Liang and MA Shao 2005. Change of antioxidative enzymes and MDA among 10 wheat genotypes at maturation stage under soil water deficits. Colloid. Surf. B: Biointerf. 45(2): 7-13.

Sharma SS and KJ Dietz 2006. The significance of amino acids and amino-acid derived molecules in plant responses and adaptation to heavy metal stress. J. Exp. Bot. 57(4): 711-726.

Shen W, K Nada and S Tachibana 2000. Involvement of polyamines in the chilling tolerance of cucumber cultivars. Plant Physiol. 124: 431-439.

Shi JP, GM Li and SM Chi 1994. The effect of calcium on endogenous hormones of maize seedlings under water stress. J. Hebei Agric. Univ. 17: 48-51.

Shindy WW and O Smith 1975. Identification of plant hormones from cotton ovules. Plant Physiol. 55: 550554.

Singh DK, PWG Sale, CK Pallaghy and V Singh 2000. Role of proline and leaf expansion rate in the recovery of stressed white clover leaves with increased phosphorus concentration. New Phytologist 146(2): 261-269. 
Strauss G and H Hauser 1986. Stabilization of lipid bilayer vesicles by sucrose during freezing. Proc. Natl. Acad. Sci. USA 83: 2422-2426.

Subrahmanyam D, YS Subash, A Haris and AK Sikka 2006. Influence of water stress on leaf photosynthetic characteristics in wheat cultivars differing in their susceptibility to drought. Photosynthetica 44: 125-129.

Türkan I and T Demiral 2009. Recent developments in understanding salinity tolerance. Environ. Exp. Bot. 67: 2-9.

Vendruscolo ECG, I Schuster, M Pileggi, CA Scapim, HBC Molinari, CJ Marur and LGE Vieira 2007. Stress-induced synthesis of proline confers tolerance to water deficit in transgenic wheat. J. Plant Physiol. 164(10): 1367-1376.

Vernon LP and GR Seely 1966. The chlorophylls. Academic Press, New York.

Vogel AJ 1975. A text book of practical organic chemistry, 3rd ed., Book Society and Longman Group Ltd., London.

Vranova E, D Inzé and FV Breusegem 2002. Signal transduction during oxidative stress. J. Exp. Bot. 53: 1227-1236.

Yadav VK, V Gupta and Y Nyflam 1999. Hormonal regulation of nitrate in gram (Cicer arietinum) genotypes under drought. Indian J. Agric. Sci. 69: 592-595.

Zhang ML Duan, X Tian, Z He, J Li, B Wang and Z Li 2006. Uniconazole- induced tolerance of soybean to water deficit stress in relation to changes in photosynthesis, hormones and antioxidant system. J. Plant Physiol. 6: 1-21.

Zhou X, R Minocha and C Minocha 1995. Physiological responses of suspension cultures of Catharanthus roseus to aluminum: changes in polyamines and inorganic ions. J. Plant Physiol. 145: 277-284.

(Manuscript received on 23 May, 2011; revised on 25 May, 2011) 